\title{
The Current Trends in the Right of Assembly under the European Convention on Human Rights
}

\author{
By Petr Černy"
}

\begin{abstract}
The right of assembly is one of the most important political rights. This right, together with freedom of speech and the right to associate, is the basis of every civil society. In particular, it enables everyone to comment on public affairs, get information, share it with other people, and also influence public opinion. This right is especially important in times of social changes. The European Court of Human Rights (ECHR), seated in Strasbourg, protects compliance for the European Convention on Human Rights and assesses, inter alia, whether the member states violated the right of free assembly. The application of article 11 of the Convention raises a number of questions about the scope of the possibility to restrict the right of assembly. Member States of the Convention sometimes face the question whether to ban the assembly of the enemies of democracy or whether the right of assembly can be abuse to prevent other assemblies by blocking the route of march, for example. This paper deals with the ECHR's approach to these issues as well as the concept of right of assembly according to the Convention. At the same time it follows the evolution of the opinion on this right over time.
\end{abstract}

Keywords: European Convention on Human Rights; European Court of Human Rights; Freedom of Speech; Property Law; Right of Assembly.

\section{Introduction}

The right of assembly is considered one of the fundamental rights and is guaranteed in both the constitutional documents of European states and in Article 11 of the European Convention on Human Rights (hereinafter referred to as 'the Convention'):

1. Everyone has the right to freedom of peaceful assembly and to freedom of association with others, including the right to form and to join trade unions for the protection of his interests.

2. No restrictions shall be placed on the exercise of these rights other than such as are prescribed by law and are necessary in a democratic society in the interests of national security or public safety, for the prevention of disorder or crime, for the protection of health or morals or for the protection of the rights and freedoms of others. This article shall not prevent the imposition of lawful restrictions on the exercise of these rights by members of the armed forces, of the police or of the administration of the State.

\footnotetext{
*Assistant Professor, Faculty of Social and Economy Studies, University Jan Evangelista Purkyně, Czech Republic. E-mail: petr.cerny@ujep.cz
} 
The European Court of Human Rights (hereinafter referred to as 'ECHR') interprets the rights enshrined in the Convention and provides member states with a basic framework of the level of human rights.

Historically, the right of assembly in continental Europe originated in the $18^{\text {th }}$ century as a purely political right along with other political rights. It was about gaining the opportunity for citizens to speak together at the assembly against the absolutist state. Initially, political parties emerged as the most socially influential organizations in the execution of the right of assembly, and only in the last few decades other social movements that are not oriented towards seizing power in the state, have emerged.

In a current democratic state (as opposed to an absolutist, totalitarian or autocratic state), this freedom as well as other freedoms is taking on a broader dimension which allows them, with regard to the possibility of creation of public opinion, to discuss and address all issues which are of major importance for society. This makes the right of assembly one of the structural elements of democracy. This situation is also reflected in the Convention, in which the right of assembly is not described as a political right, and its interpretation applies the protection of assemblies even to completely non-political assemblies.

The right of assembly often also serves to informal control of the exercise of power in the state, to the possibility to express oneself critically towards representatives of public life. Sometimes the assembly is the only effective way of expressing for certain groups of the population, or representatives of minority views in general, who do not have access to the media or at least enough funds to spread their ideas. The assembly gives a certain added value to the expressed opinion, because the presence of a certain number of people at a particular place strengthens the weight of the expressed attitude and gives it a certain emotional dimension.

\section{Relation to the Freedom of Expression}

The right of assembly is closely related to freedom of expression, which is a central political right. Due to the interpenetration with other rights we can call it the universal right or super-freedom. Without the opportunity to express ideas or opinions the other political rights would be meaningless. What good would the possibility to gather with others be to the person if they could not express common views? If freedom of expression cannot be restricted in a certain area (e.g. only because shocking and offensive ideas are presented), freedom of assembly cannot be restricted for this reason either. The right of assembly is one of the important rights by which freedom of expression is exercised.

Without freedom of expression, it is difficult to imagine participating in the solution of public issues and problems, participating in elections or the possibility of obtaining information without being able to disseminate them further. Freedom of expression is one of the most important foundations of a democratic society and one of the main conditions for its progress and the development of any individual. 
Article 10 of the Convention guaranteeing freedom of expression does not provide for specific forms of expression, from which it is possible to deduce the possibility to express oneself in all forms imaginable. One is therefore free to express himself in writing, orally, in print, in images, by symbolic actions, such as wearing a uniform, by songs, by music, by different types of clothing, etc. The speech does not have to necessary relate directly to participation in political issues.

According to the ECHR, freedom of assembly and the right to express opinions through it are among the overriding values of a democratic society. According to the ECHR, freedom of assembly must also be interpreted with regard to the exercise of freedom of expression, since the right to hold opinions and the right to disseminate those opinions are an integral part of freedom of assembly ${ }^{1}$. In some judgments, the ECHR even goes so far as to explicitly mention that it has interpreted Article 11 of the Convention in the present case in the light of Article 10 of the Convention ${ }^{2}$. It should also be noted that the ECHR considers the right of assembly to be a lex specialis to freedom of expression, as it may also interfere with the right of assembly without interfering with freedom of expression. This will be the case when there is a ban on the assembly before its realisation or in the case of the organization of an unauthorised assembly ${ }^{3}$. On the other hand, in the case of a ban on the assembly for chanting certain slogans and opinions, it will interfere with both rights ${ }^{4}$.

The ECHR often states in its decisions that the essence of democracy is its ability to solve problems through open discussion. Radical preventive measures that suppress the right of assembly and freedom of expression in cases other than incitement to violence or rejection of democratic principles - as shocking and unacceptable some views and words may seem to state authorities, and as illegitimate the demands may be, they render a disservice to democracy and often even threaten it. In a democratic society based on the rule of law, political ideas which call into question the existing order and the implementation of which is advocated by peaceful means must be given a fair opportunity to express themselves through the exercise of the right of assembly as well as other legal means. If any likelihood of tensions or intense communication between opposing groups during the event were to justify banning it, society would be deprived of the opportunity to hear differing views on any issue that offends majority opinion ${ }^{5}$.

The right of assembly is therefore one of the ways in which minorities in society, which may not be accepted by the majority society, can present and express themselves. One example is the case of Alexeyev v. Russia solved by the $\mathrm{ECHR}^{6}$. In this case gay community marches were banned to alert the public to discrimination against this minority in Russia (the marches were called either Pride March or Gay Pride). Moscow municipal authorities have banned these assemblies, with reference to violations of the rights of others, namely those who

\footnotetext{
${ }^{1}$ Refah Partisi and Oth. v. Turkey (2003); Öllinger v. Austria (2006).

${ }^{2}$ Sergey Kuznetsov v. Russia (2008); Körtvélyessy v. Hungary (2016).

${ }^{3}$ Kudrevičius and Oth. V. Lithuania (2015).

${ }^{4}$ Cf. Ezelin v. France (1991), Galstyan v. Armenia (2007), and Barraco v. France (2008).

${ }^{5}$ Pilot judgment of ECHR Stankov and the United Macedonian Organisation Ilinden v. Bulgaria (2001).

${ }^{6}$ Alexeyev v. Russia (2010).
} 
have a negative attitude toward homosexuality out of religious or moral beliefs. They argued that the state must also consider the requirements of major religious associations that demanded a ban on assemblies. In the ruling, the ECHR pointed out that the mayor of Moscow had repeatedly publicly expressed his determination to prevent gay marches, because the promotion of homosexuality should be according to him incompatible with the religious doctrines and moral values of the majority. The ECHR stated, inter alia, that democracy did not mean that the opinion of the majority must always prevail and that only the moral values of officials were reflected in the ban on assemblies, so it did not consider the ban on marches necessary in a democratic society and delivered a ruling on violation of Article 11 of the Convention.

However, the ECHR grants freedom of expression as well as freedom of assembly different degrees of protection depending on the purpose and area of public life in which these rights are to be exercised. It attaches the great importance to the freedom of expression in the political debate and considers that only very compelling reasons are needed to justify a restriction on political expression ${ }^{7}$. Political expression can be defined relatively broadly as an expression of a person's will to participate in solving public problems or to express an attitude towards certain issues of general interest.

Furthermore, it is important to realise that freedom of expression in connection with the right of assembly are not unrestricted and are not intended to intimidate groups of the population or opponents in opinions, but primarily to address societal issues. In this connection the judgment in Vona v. Hungary ${ }^{8}$ can be recalled, which involved dissolution of the far-right civic association (Hungarian Guard Movement). This association organised demonstrations and marches in places with a significant Roma population with participants numbering tens to hundreds of people evoking in their clothing, symbols and speeches and slogans the fascist regime of the Arrow Crosses governing in Hungary in the 1940s. The activities and manifestations of this movement were verbally and visually based on the racially based distinction between the Roma minority and the Hungarian majority. Referring to previous case law the ECHR has stated that as in the case of freedom of expression, ideas or actions cannot be excluded from the protection of the Convention simply because they raise concerns in a certain group of people or are perceived by some as disrespectful. However, the court noted that although there was no immediate violence in the marches organised by the movement, the marches were capable of expressing the intention and ability of their organisers to use the paramilitary group for achieving the objectives that evoked the Arrow Crosses as a pillar of the regime responsible for mass massacre of Roma in Hungary. The ECHR further considered that the effect of these marches was enhanced by the association's connection with the Hungarian Guard Association as a registered association enjoying legal recognition. In the light of Hungary's historical experience, speeches during demonstrations and marches could intimidate a racial minority, especially when their members were witnesses in their

\footnotetext{
${ }^{7}$ Feldek v. Slovakia (2001).

${ }^{8}$ Vona v. Hungary (2013).
} 
homes as involuntary audiences. According to the ECHR, such conduct does not enjoy the protection of the Convention.

Another important rule in the application of the Convention follows from the ECHR case law, namely that illegal activities and manifestations that occur at the assembly cannot be attributed indirectly to the organisers of the assembly, unless it is proven that the individuals concerned were directly involved in these activities?

Reference may be made to the case of Štefanec v. Czech Republic ${ }^{10}$ were assembly was organised even after it was prohibited after proper notification (by a person other than Mr. Štefanec). It was proven that Mr. Štefanec led the procession and communicated with the police and the participants of the assembly through a megaphone. Provisions of national law made it possible, inter alia, to penalise those who convene or hold a prohibited assembly. Mr. Štefanec denied that he was the convener or organiser of the assembly. It follows from the ECHR judgment that only the declaration of a person as an organiser is not sufficient, but it is necessary to prove that this person actually took care of the course of the meeting, organised it and directed its course. In the given case, the key evidence were video recordings from the assembly, however, they were not sufficient to prove that $\mathrm{Mr}$. Stefanec, for example gave instructions to move the assembly, etc.

\section{The Term of Assembly}

One of the key issues in the application of the Convention is the definition of assembly and the resulting protection granted by the Convention. Where an assembly can be defined as an assembly under Article 11 of the Convention, it follows that the assembly is under increased protection against interference of the State and third parties, which must respect the application of this fundamental right. Conversely, unless it is an assembly under the protection of the Convention, it may be restricted by ordinary legal prohibitions. Such case may be an assembly of witnesses to a traffic accident or a queue in front of a shop, etc. These assemblies may be dissolved or otherwise restricted through ordinary police law.

Assemblies within the meaning of the Convention are generally considered to be both private and publicly accessible assemblies of persons, as well as street processions, i.e. assemblies not limited to one place, whose participants have a common goal. While applying Article 11 of the Convention, the ECHR is based on the concept of 'assembly' as a grouping of many individuals, processions, and public parades in a peaceful form. The term assembly under the Convention includes prolonged occupation of buildings ${ }^{11}$, political, religious ${ }^{12}$, cultural $^{13}$,

\footnotetext{
${ }^{9}$ Yilmaz and Kiliç v. Turkey (2008).

${ }^{10}$ Štefanec v. Czech Republic (2006).

${ }^{11}$ Cissé v. France (2002).

${ }^{12}$ Barankevich v. Russia (2007).

${ }^{13}$ Gypsy Council v. UK (2002).
} 
social, or other gatherings, including exhibitions, concerts, trade fairs, seminars, and receptions ${ }^{14}$.

It should be recalled here that Article 11 of the Convention protects only peaceful assemblies. This means, among other things, that the assembly is not convened for the purpose of committing violence, riots, and other illegal acts or that these activities are not organised by the convener or another person (organiser) during the meeting. Minor incidents during the assembly do not make the assembly restless ${ }^{15}$.

The occupation of buildings as a form of assembly is undoubtedly one of the most disputable forms of assembly, as there is a sharp conflict between property rights and the right of assembly. Here comes the question of how to deal with an assembly that intentionally occupies someone else's property (so-called squatting). The fundamental question is whether such an event is an assembly and whether it is protected by Article 11 of the Convention. This action often involves people demonstratively occupying abandoned buildings, posting political statements, or even holding supportive actions in them, and refusing to leave an occupied building even by means of passive resistance. Thus, it is obviously not a simple squatting consisting in obtaining housing in abandoned properties, but at the same time a civically active attitude presented externally.

One of the means of keeping a property occupied is to declare its new inhabitants to be participants in the assembly, who are demonstrating a socially important topic by their action. Since only peaceful assemblies enjoy constitutional protection, if violence is used when entering the building (breaking of locks, etc.), this action cannot be subsumed under the protection of the right of assembly.

The ECHR judgment in Cissé v. France ${ }^{16}$ is often mentioned in this context. In this case, however, it was a specific situation. With the consent of ecclesiastical authorities, French immigrants occupied and inhabited the French church for a long time to draw attention to the disproportionately strict French immigration laws and called for their change. Following the worsening of the hygiene situation, the assembly was dissolved by the French police, which the ECHR found to be a legitimate reason for ending the assembly.

With the changes in society and its development, new questions arise regarding the choice of the place where the assembly can take place, and there are further conflicts between the right of ownership and the right of assembly. In Appleby v. The United Kingdom ${ }^{17}$, the complainants argued that they could not hold a meeting in a city shopping centre belonging to a private individual. However, this centre was first built by a legal entity established by the city, which then transferred the centre to private hands. The complainants argued that the shopping centre was not only a shopping centre, but also a social centre where people met, and had several other functions. In this case, the ECHR considered

\footnotetext{
${ }^{14}$ Djavit An v. Turkey (2003); /92; Bączkowski and Others v. Poland (2007); Sergey Kuznetsov v. Russia (2008); European Commission of Human Rights decision in Rassemblement Jurassien Unité Jurassienne v. Switzerland (1970).

${ }^{15}$ European Commission of Human Rights decision in Christians against Racism and Fascism v. UK (1980); Stankov and United Macedonian Organisation Ilinden v. Bulgaria (2001).

${ }^{16}$ Cissé v. France (2002).

${ }^{17}$ Appleby v. UK (2003).
} 
that the centre is marked on maps as an urban centre providing several other services and participating in the cultural and social life of the city. The ECHR stated that due to democratic, social, economic and technological developments, a positive obligation of the state may arise to enforce exercising of the right of assembly also towards a private entity, especially if it is a private entity in some way connected with a public institution. However, in the present case, he considered that the complainants had ample opportunities to exercise their right of assembly without restricting private property, as they could demonstrate (set up an information stand) at the centre's entrances, on its galleries or negotiate with individual traders within the centre, they could also hold their meetings in the old city centre, which is why the ECHR did not find there a positive obligation from the state and a violation of Article 11 of the Convention.

This judgment can also be approached relatively critically, with reference to the development of society and the real privatization of several public services provided so far by the state, such as transport, post, energy supply, and healthcare. The question is whether, even in this situation, property rights should prevail over other rights and whether the state should ensure a fair balance of these rights. In this case, there was no doubt that the premises were set up from public funds and, even after being transferred to private hands, served as a quasi-public space (forum publicum). In this project, that was transferred to private hands as a new building, public money and public interests were present. This centre was located near public institutions. It is difficult to accept the view that, through privatization, public authorities will be relieved of their responsibility to meet the needs of the population and to ensure the realization of fundamental human rights and freedoms. In the current conditions, the view that the private owner can expel anyone from his land indefinitely is completely unsustainable.

We can therefore state that the assembly can also take place inside the building, but the right of assembly itself does not automatically entitle the occupation of third-party property. In general, there is no right to choose a forum where persons would like to exercise their right of assembly, if it can be exercised elsewhere. However, there is a relevant number of views, also presented in the ECHR case law, that in certain cases the right of ownership has to give way and is not inherently unlimited, but when this is to happen has not yet been comprehensively and satisfactorily resolved.

With regard to the purpose of the assembly for which the assembly is held, the ECHR, on the one hand, acknowledges that the official purpose of the assembly may be different from the actual (illegal) one, but immediately adds that these facts need to be verified in practice, i.e. how subject is going to behave $\mathrm{e}^{18}$. It is not possible to deduce from the case law of the ECHR a tendency to preventive prohibitions of assemblies before their holding, if the declared purpose of the assembly is harmless. Nor can the ban on an assembly be based solely on the fact that in the past some participants in the assembly were violent ${ }^{19}$.

\footnotetext{
${ }^{18}$ Stankov and the United Macedonian Organisation Ilinden v. Bulgaria (2001); Tsonev v. Bulgaria (2006).

${ }^{19}$ E.g. Primov and Oth. v. Russia (2014).
} 
However, the ECHR allows for the establishment of restrictive conditions for hold of an assembly, including the obligation to notify the assembly in advance to balance the various interests protected. Regarding the announcement of the assembly, the ECHR stated that since the assembly in a public place could in some way disrupt everyday life and may face disapproval, it is important that the organiser of the assembly complies with the rules laid down by law for announcing the assembly. In addition, such an obligation is also to the benefit of the participants in the assembly, as the notification of the assembly in advance allows the police to prepare for the event and to ensure its smooth running ${ }^{20}$. Although a number of legal regulations of European states (e.g. German, Austrian, Polish, Czech, Slovak) contain the reporting principle of the Assembly, which means that it is sufficient to report the intention of holding as assembly to the authority, in accordance with the Convention is the authorization principle consisting in the possibility to hold the assembly only after the authority has granted permission to hold it (e.g. Russian, Lithuanian) ${ }^{21}$.

\section{Interventions in the Right of Assembly}

Another major issue of the right of assembly is the question of what interventions in the right of assembly are permissible and under what conditions they can be carried out. Article 11 of the Convention foresees three cumulative conditions which justify an interference with the right of assembly, namely (a) the interference must be effected by law; (b) it must pursue one of the legitimate objectives set out in Article 11 (2) of the Convention; and (c) it must be necessary in a democratic society, that is, proportionate to the objectives it pursues.

State interference in the right of assembly can take many different forms. The most common type of intervention is a ban on the assembly before it takes place ${ }^{22}$ and the dissolution of the assembly during the assembly ${ }^{23}$. However, the ECHR has described in its case law several other interventions as interfering with the right of assembly. These included, for example, criminal sanctions against demonstrators $^{24}$, detention at a police station $^{25}$, imposition of a fine in administrative proceedings ${ }^{26}$, restriction of the date of the meeting or place of the meeting ${ }^{27}$, diversion of the meeting to another place ${ }^{28}$ or evacuation of the church in case of its occupation ${ }^{29}$.

\footnotetext{
${ }^{20}$ Barraco v. France (2009); Oya Ataman v. Turkey (2006).

${ }^{21}$ Sergey Kuznetsov v. Russia (2008).

${ }^{22}$ Bączkowski and Oth. v. Poland (2007).

${ }^{23}$ Akgöl and Göl v. Turkey (2011); Primov and Others v. Russia (2014).

${ }^{24}$ Yilmaz and Kiliç v. Turkey (2008); Kudrevičius and Others v. Lithuania (2015); Kakabadze and Oth. v. Georgia (2012).

${ }^{25}$ Samüt Karabulut v. Turkey (2009).

${ }^{26}$ Alekseyev v. Russia (2010).

${ }^{27}$ Hyde Park v. Moldova (2009); Patyi v. Hungary (2012); Yilmaz Yildiz and Oth. v Turkey (2014).

${ }^{28}$ The United Macedonian Organisation Ilinden and Ivanov v. Bulgaria (2005).

${ }^{29}$ Cissé v. France (2002).
} 
However, in connection with interferences with the right of assembly, it must be emphasised that the finding of the existence of an interference does not automatically mean that Article 11 of the Convention has been violated. It depends on whether this interference passes a review algorithm, which is the same for both interference with freedom of expression and interference with the right of assembly. This review algorithm can be divided into five steps, which can be expressed in the form of questions: 1) Does the present case fall under Article 11 of the Convention?; 2) Was it an interference with the right of the assembly of the complainant?; 3) Was this intervention in accordance with the national law ? $^{30}$; 4) Does the intervention pursue at least one of the legitimate objectives set out in Article 11 (2) of the Convention?; and finally 5) Was this intervention necessary in a democratic society? ${ }^{31}$ In some of its decisions, the ECHR takes a test consisting only of questions 3 ) to 5$)^{32}$.

It should be noted here that the possibilities of interfering with the right of assembly are slightly wider than in the case of the possibilities of interfering with freedom of expression or freedom of thought guaranteed in Articles 8 and 9 of the Convention. In addition, Article 11 (2) of the Convention allows for the imposition of legal restrictions on members of the armed forces, the police, and the administration. In practice, this means that the right to demonstrate may be restricted by law to a significant part of the population linked to the service of the state.

States have an obligation not only to allow the exercise of the right of assembly and, in certain cases, to set the conditions for its holding, or even to ban it, but they are also obliged to actively ensure the realization of the assembly so that it can take place despite possible counterdemonstrations ${ }^{33}$. What all the state authorities (i.e. especially the police) must ensure so that the positive obligation of the state to ensure the implementation and protection of the assembly is fulfilled cannot be clearly find from the case law. In general, states enjoy a wide margin of discretion as to what specific steps to take, and it is important that they are effective and proportionate.

In 1988, the $\mathrm{ECHR}^{34}$ stated that demonstrations must not be attacked by persons who contradict the ideas and claims to be presented. Participants must be able to attend meetings without fear of physical violence; such a fear could discourage associations or other groups promoting common ideas or interests from openly expressing their views on highly controversial issues that affect society. In a democracy, the right to counterdemonstration cannot be extended to block the exercise of the right to demonstrate. True real freedom of peaceful assembly cannot be reduced to a mere obligation of the state not to intervene.

\footnotetext{
${ }^{30} \mathrm{ECHR}$ also calls for a certain quality of this law, as it must be accessible to the person concerned and must be foreseeable as to its effects.

${ }^{31}$ What is assessed are on the one hand public interests protected by Article 11 (2) of the Convention and, on the other hand, the requirements for the free expression of opinion by persons gathered on the streets or in public places, e.g. Skiba v. Poland (2009) and Fáber v. Hungary (2012).

${ }^{32}$ E.g. Primov and oth. v. Russia (2014); DISK and KESK v. Turkey (2012).

${ }^{33}$ Öllinger v. Austria (2006).

${ }^{34}$ Plattform „Ärzte für das Leben“ v. Austria (1988).
} 
Another principle applied in addressing the adequacy of interventions in the right of assembly is the principle of subsidiarity of interventions, although it is not explicitly called like that by the ECHR. This means that a more intensive intervention cannot be used if a less intensive intervention would be sufficient to fulfil the objective. For example, if the assembly is to take place in a park that does not have sufficient capacity for the reported number of demonstrators, this is not a reason to ban the assembly but rather to set a condition to limit the number of demonstrators ${ }^{35}$.

Part of the implementation of the right of assembly may be the restriction of the normal way of life or transport ${ }^{36}$ as a side effect of the assembly, this is not by itself a reason to prohibit the assembly. However, for example, blocking traffic or other activities must not be the aim of the assembly in order to put pressure on the responsible authorities ${ }^{37}$.

Another question is how the state authorities should behave in the event of an unannounced assembly, either for failure to comply with the obligation of the convener or because it is an assembly created spontaneously without the convener (e.g. the participants of the assembly meet in front of the government building at the time of the hearing of the essential issues without anyone inviting them to attend the meeting).

Regarding unannounced peaceful assemblies a distinction must be made between spontaneous assemblies and non-spontaneous assemblies. Spontaneous assemblies enjoy essentially the same protection as permitted assemblies. Conversely, unannounced assemblies that cannot be considered spontaneous enjoy less protection; according to the case law of the ECHR, such assemblies may be dissolved under certain circumstances ${ }^{38}$. However, this interference with the right of assembly must take into account the number of persons and the nature of the place of assembly and, if possible, leave at least a small amount of time for the demonstrators to express their views in undisturbed way ${ }^{39}$. Thus, spontaneous, or non-spontaneous unannounced (and peaceful) assemblies cannot be automatically dissolved simply because they have not been announced in advance. If a national authority does so, there is a risk that such interference will be found by the ECHR to be a disproportionate interference with the freedom of peaceful assembly.

\section{Conclusion}

Although the case law on the right of assembly is not as developed as the case law on freedom of expression, given the decades-long work of the ECHR and the Commission before, this case law also provides sufficient guidance in the application of Article 11 of the Convention. The nature of interference with

\footnotetext{
${ }^{35}$ Cf. Primov and Oth. v. Russia (2014); Barankevich v. Russia (2007).

${ }^{36}$ Körtvélyessy v. Hungary (2016); United Civil Aviation Trade Union and Csorba v. Hungary (2018).

${ }^{37}$ Kudrevičius and Oth.v. Lithuania (2015); Galstyan v. Armenia (2007); Primov and Oth. v. Russia (2014).

${ }^{38}$ Bukta and Oth. v. Hungary (2007); Éva Molnár v. Hungary (2008).

${ }^{39}$ Samüt Karabulut v. Turkey (2009).
} 
the right of assembly is usually repeated as is clear from the case-law from recent years. In the ECHR's decisions on the right of assembly can therefore be traced clear lines of thought of the interpretation and application of this right. The ECHR itself seeks inspiration for the principles applied in cases of freedom of expression in solving problems related to the right of assembly. For this reason, it is useful to know these principles relating to freedom of expression, as they provide guidance on new issues in addition to the issues already resolved.

It is not surprising and it is a long-term trend evident from the ECHR case law that Member States that are generally prone to authoritarian regimes and lower standards of human rights protection come before the ECHR with the most serious violations of assembly law, including criminal sanctions for organizing assemblies or violent repression of demonstrations. However, new problems which show the development of society are also emerging. An example is the problem of the conflict between the right of ownership and the right of assembly, as it is no longer possible to say that the right of ownership took precedence and it was not possible to hold an assembly on his property without the consent of the owner. The conditions under which this is and is not possible are not yet fully clarified and will be the subject of further cases held before the ECHR and the courts of the Contracting States.

\section{References}

The Convention - the European Convention on Human Rights (The Convention for the Protection of Human Rights and Fundamental Freedoms), came into force in 1953.

\section{Cases}

\section{European Court of Human Rights}

Akgöl and Göl v. Turkey, dated 17.5.2011, App. nos. 28495/06 and 28516/06 Alexeyev v. Russia, dated 21.10.2010, App. nos. 4916/07, 25924/08,14599/09 Appleby v. UK, dated 6. 5. 2003, App. no. 44306/98

Bączkowski and Others v. Poland, dated 3.05.2007, App. no. 1543/06

Barankevich v. Russia, dated 26.07.2007, App. no. 10519/03

Barraco v. France, dated 5. 3. 2009, App. no. 31684/05

Bukta and Others v. Hungary, dated 17.07.2007, App. no. 25691/04

Cissé v. France, dated 9.04.2002, App. no. 51346/99

DISK and KESK v. Turkey, dated 27.11.2012, App. no. 38676/08

Djavit An v. Turkey, dated 20.02.2003, App. no. 20652/92

Éva Molnár v. Hungary, dated 7.10.2008, App. no. 10346/05

Ezelin v. France, dated 26.04.1991, App. no. 11800/85

Fáber v. Hungary, dated 24.07.2012, App. no. 40721/08

Feldek v. Slovakia, dated 12.07.2001, App. no. 29032/95

Galstyan v. Armenia, dated 15.11.2007, App. no. 26986/03

Galstyan v. Armenia, dated 15. 11. 2007, App. no. 26986/03

Gypsy Council v. UK dated 14.05.2002, App. no. 66336/01 
Hyde Park v. Moldova, dated 7.04.2009, App. no. 18491/07

Kakabadze and Others v. Georgia, dated 2.10.2012, App. no. 1484/07

Körtvélyessy v. Hungary, dated 5.04.2016, App. no. 7871/10

Kudrevičius and Others v. Lithuania, dated 15.10.2015, App. no. 37553/05

Öllinger v. Austria, dated 29.06.2006, App. no. 76900/01

Oya Ataman v. Turkey, dated 5.12.2006, App. no. 74552/01

Refah Partisi and Others v. Turkey, dated 13.02.2003, App. no. 41340/98

Patyi v. Hungary, dated 17.01.2012, App. no. 35127/08

Plattform „Ärzte für das Leben“ v. Austria, dated 21.6.1988, App. no. 10126/82

Primov and Others v. Russia, dated 12.06.2014, App. no. 17391/06

Samüt Karabulut v. Turkey, dated 27.01.2009, App. no. 16999/04

Sergey Kuznetsov v. Russia, dated 23.10.2008, App. no. 10877/04

Skiba v. Poland, dated 7.07.2009, App. no. 10659/03

Stankov and the United Macedonian Organisation Ilinden v. Bulgaria, dated 2.10.2001, App. nos. 29221/95 and 29225/95

Štefanec v. Czech Republic, dated 18.07.2006, App. no. 75615/01

Tsonev v. Bulgaria, dated 13.04.2006, App. no. $45063 / 99$

United Civil Aviation Trade Union and Csorba v. Hungary, dated 22.5.2018, App. no. $27585 / 13$

United Macedonian Organisation Ilinden and Ivanov v. Bulgaria, dated 20.10.2005, App. no. $44079 / 98$

Vona v. Hungary, dated 9.07.2013, App. no. 35943/10

Yilmaz and Kiliç v. Turkey, dated 17.07.2008, App. no. 68514/01

\section{European Commission of Human Rights}

Christians against Racism and Fascism v. UK, dated 16.7.1980, App. no. 8440/78

Rassemblement Jurassien Unité Jurassienne v. Switzerland, dated 10.10.1979, App. no. $8191 / 78$ 